\title{
Strategies for continuous improvement in the master's degree in "Colour Technology for the automotive sector" based on feedback from graduates
}

\author{
E. Perales, B. Micó-Vicent, V. Viqueira, K. Huraibat, F.M. Martínez-Verdú \\ Grupo de Visión y Color. Universidad de Alicante. esther.perales@ua.es
}

\begin{abstract}
The first edition of the Master's Degree in "Color Technology for the Automotive Sector" was held during the last academic year. The academic results in terms of qualifications, achievement and learning were good. In spite of the good sensations, there are aspects to be improved, both in methodology and the development of the subjects, timing of the contents, organization or communication channels. Following this line, the Academic, agreed on a plan of continuous improvement based on the feedback provided by the graduate surveys. A specific survey was carried out to gather their specific experience of the course in order to be able to modify the general strategy of the master's degree at the teaching and organisational level. The objectives were to adapt the teaching methodology to facilitate a more reflexive, participative and autonomous learning with a high degree of involvement and motivation of the students, to improve the academic results in terms of learning and satisfaction, to simplify and improve the logistic management of the course, etc. Thus, the survey included questions relating to the usefulness of the master's degree, methodology, organisation and planning of teaching, as well as a final question relating to the overall satisfaction of the course. A short survey was chosen with only 10 questions that the student rated from 1 to 5 on a scale from "strongly disagree" to "strongly agree". From the analysis of the responses, some important weaknesses were detected, such as the lack of content developed in video format, and the slowness of feedback on the results obtained in the proposed tasks. Based on these results, it was proposed an improvement plan that included the incorporation of videos to teaching materials, flexibility in the deadlines for activities, and the periodic monitoring of student learning and concerns through "Adobe Connect".
\end{abstract}

Keywords:Feedback, b-learning, Moodle 
Strategies for continuous improvement in the master's degree in "Colour Technology for the automotive sector" based on feedback from graduates

\section{Introduction}

During the course 2016-2017, teachers from the Color and Vision Group belongs to the University of Alicante launched the first edition of the Master's Degree in Colour Technology for the Automotive Sector (ColTAS). The purpose of ColTAS Master is to provide a comprehensive training in the multidisciplinary study of Colour Science and Technology from a global perspective. Color technology focuses on the study of theories and techniques related to the design, manufacture and measurement of colored materials (Open Course Ware, 2009) In addition, dfferent industrial sectors are involved in color technology (colorants, coatings, textiles, ceramics, plastics, printing, multimedia, etc.) therefore it is a discipline very important and it is necessary a perfect knowledge to a correct process. However, in many cases, color experts within these sectors have not received any specific training in color science but through practical, possible self-taught, experience. This Master of 60 ECTS or credits (one academic year, from September to June) is managed by the Continuing Education Centre (CEC-UA), and organized by the Business School of the General Foundation of the University of Alicante and the Department of Optics, Pharmacology and Anatomy, belonging to the Faculty of Sciences of this University. The syllabus is composed by 12 different subjects divided into two subdegrees: Expert in Color Science, Specialist in Color Engineering for the Automotive Sector and MSc in Color Technology for the Automotive Sector. This course includes an industry-based internship of up to 300 hours and provides a great opportunity to achieve basic and advanced color control skills at an industrial level, particularly in the automotive sector.

This master course is very demanding by the industrial sector, thus, there are different student profiles and different training profiles: very specific profiles with high training in this sector but without experience in colour technology, and newly graduates with the aim to get specific training to find a good job. Therefore, the adaptive learning methodology is needed to consider different factors. The adaptive learning method implies the use of materials adapted to each profile to take into account the individual characteristics of each student to optimize the training (Dwi-Surjono, 2014; Fidalgo, 2013; García-Peñalvo, 2011; Graf, 2008; Şimşek, 2010; Xiaoqiong, 2013). On the other hand, in the current university academic context, following the guidelines developed by the European Higher Education Area (EHEA), one of the most controversial and iconic issues is how to ensure a high academic performance in order to satisfy teachers and students regarding the workload level (Martínez-Verdú, 2010) within the duration of a subject and the assimilation of abilities, both generic and specific ones, in an optimal level of traceability in order to provide a positive impact. Therefore, the design and drawing up of each teaching guide of a subject was developed taking into accountthe combination of different learning activities 
connected with the assimilation of several learning objectives and specific and general abilities.

The course is offered in blended learning mode. All the theoretical contents and activities are presented online through the Moodle platform. In addition, the course has a specific intensive face-to-face programme that includes demonstrative sessions of companies involved in color measurement and seminars by experts, in order to help students acquire or complete the inter- and multidisciplinary training received in a non-presential way during the course. The methodology are based on an adaptive teaching methodology by combining the best of b-learning and flipped classroom with different learning styles according to the student's profile, initial skills, motivation and availability with the aim of obtaining maximum performance and student satisfaction.Therefore, through the Moodle platform, activities are proposed where the student will face the solution of problems, the organization and planning of activities, the analysis and synthesis of certain situations, etc. In addition, a wide range of documentation and materials are provided for the successful follow-up of all subjects presented.

In particular, students work in three different activities: individual and team tasks and participation on forums. The individual activities are designed with three participation profiles: basic, medium and high. The intention with this approach was to increase student motivation through gamma learning (Llorens-Largo, 2016). In this way, students (players) decide voluntarily or control their level of participation, dedication, hours of dedication, etc. according to their objectives, for example, in the short term, to pass an exam; in the medium and long term: to go deeper into the subject. Group activities allow students to combine different learning styles and thinking and behavior styles, so that groups complement and optimize each other to achieve better results. Finally, the participation in forums of both the student and the teacher allow all participants to play an active role that is useful to improve the methodology proposed. The forum also allows for quick feedback, another important element in gamma learning.

After the first edition, a review of this Master was done in order to evaluate the strengths and weaknesses in order to refine the course. In this way, it is important to mention that the academic results in terms of qualifications, achievement and learning were good. In spite of the good sensations, there are aspects to be improved, both in methodology and the development of the subjects, timing of the contents, organization or communication channels. Therefore, the aim of this work was collect the students' opinion by means of a specific survey in order to be able to modify the general strategy of the master's degree at the teaching and organisational level. 
Strategies for continuous improvement in the master's degree in "Colour Technology for the automotive sector" based on feedback from graduates

\section{Methodology}

The first step was to work on the survey. The main characteristics of this survey was to develop a simple survey and with speed of completion with the aim to obtain the greatest number of responses from the students. In addition, the survey was divided into four sections but with few questions to be able to answer it in some minutes. The sections were: contents, methodology, teaching staff and academid coordination and study, dedication and motivation. Finally, the survey had a section to add a general comment or observation about the course. Therefore, the survey was:

\section{CONTENT}

1. The contents and activities are consistent with the objectives

2. Time distribution of content is appropriate

3. The sequence of subjects and themes is appropriate

4. The bibliography is suitable for following the course

\section{METHODOLOGY}

1. The theory/practice ratio is correct

2. Teacher stimulates interest in different topics

3. Participation and communication between all participants is encouraged.

4. The methodology facilitates the assimilation of the contents

5. The evaluation is consistent with the methodology used

\section{TEACHING STAFF AND ACADEMID COORDINATION}

1. The level of content is adequate

2. The advice and mentoring has been satisfactory

3. The coordination between the teaching staff has been correct

\section{STUDY, DEDICATION AND MOTIVATION}

1. The time of dedication needed to follow the course is adequate

2. The degree of effort required to follow the course is adequate

3. The use of ICTs has been adequate

4. My level of involvement was higher than expected at the beginning of the course

5. My level of satisfaction was higher than expected at the beginning of the course

The survey was done with the open access Google forms software. This software allows to send directly by email to the participants and in this way, the survey can be completed quickly from this email by using a computer or a smart phone, therefore it is very easy to get access to the survey. In addition, all the answers are collected by Excel software, thus, the data processing can be done with any software. Finally, the scale of response was from 1 to 5 on a scale from "strongly disagree" to "strongly agree". 
In the last edition (2016/17), this course had 7 students of different nationalities (Asian, European and American) and initial training (with and without university degrees). All the students completed anonymously the survey.After collecting the data, they were processed by Excel software in order to identify the weaknesses and to improve the methodology for next editions.

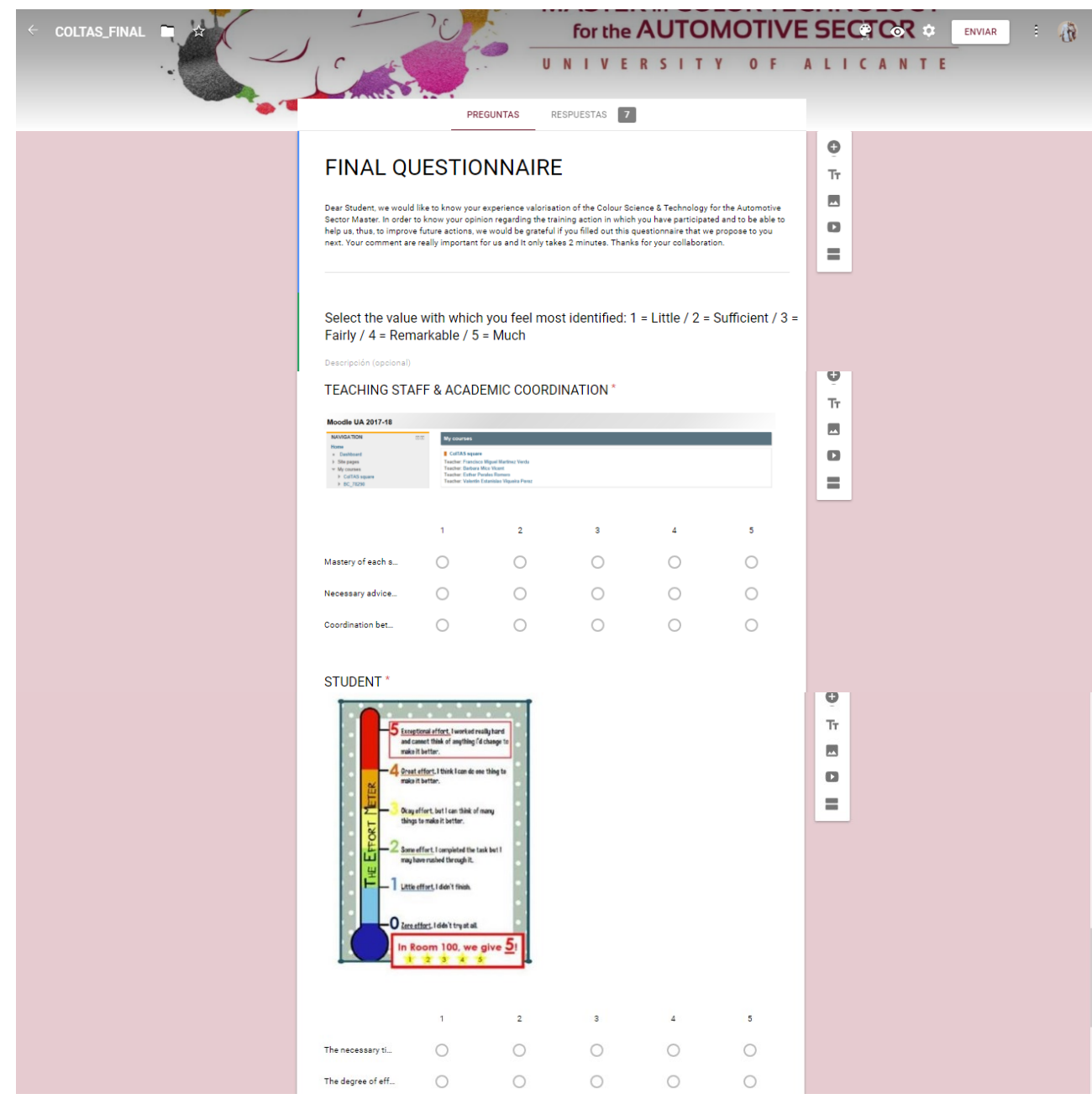

Fig. 1. Format of the survey conducted in Google Forms. Font: Moodle (2018) 
Strategies for continuous improvement in the master's degree in "Colour Technology for the automotive sector" based on feedback from graduates

\section{Results}

In this section, the results are shown divided into four groups according to the sections of the survey. Figure 2 shows the results for the Contents section. The average qualification was 3.8 above 5, what is a good result. Therefore, it can be concluded that the contents and activities were consistent with the proposed objectives with a good distribution between the different topics and subjects, and the materials developed by Moodle were quite enough and useful for monitoring the course.

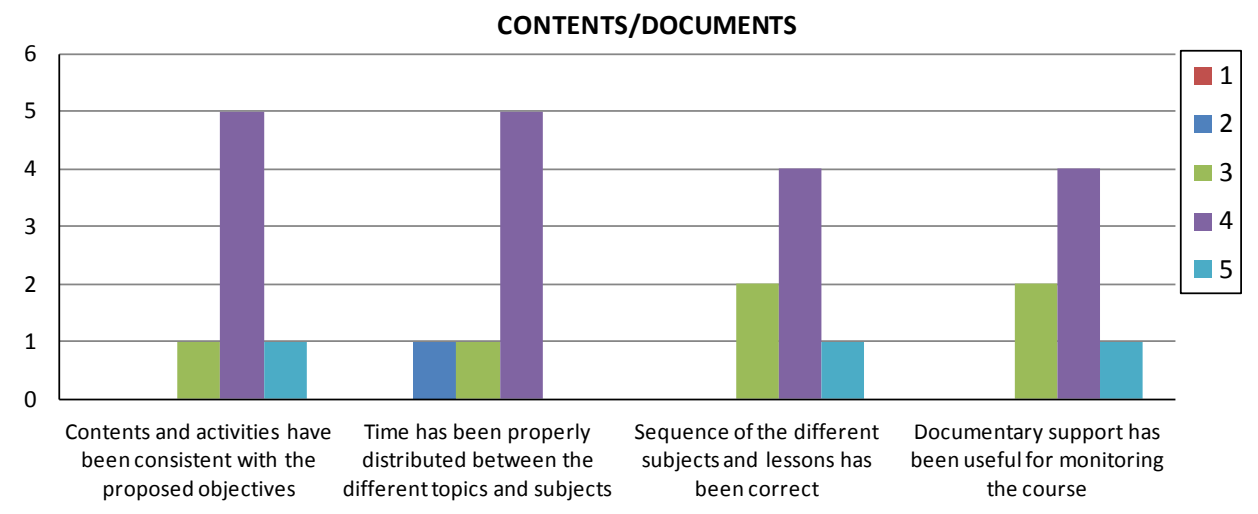

Fig. 2. Results obtained for the first sections "Contents"

Regarding the methodology, the average qualification was equal to 3.7 where the maximum satisfaction was related to the learning evaluation format which students considered appropriate for the teaching methodologies used. The low mark was for the balance between theoretical and practical contents (3.1). This mark is normal because the course is designed with a specific intensive face-to-face programme of only two weeks. Thus, the practical sessions presented in that programmeare reduced by comparing with the total course. However, in general, it can worked out that the methodology was appropriate by stimulating the interest in the different topics, with a good communication among the participants (students and teachers) and by faciliting the assimilation of the contents by means of the proposed activities. 


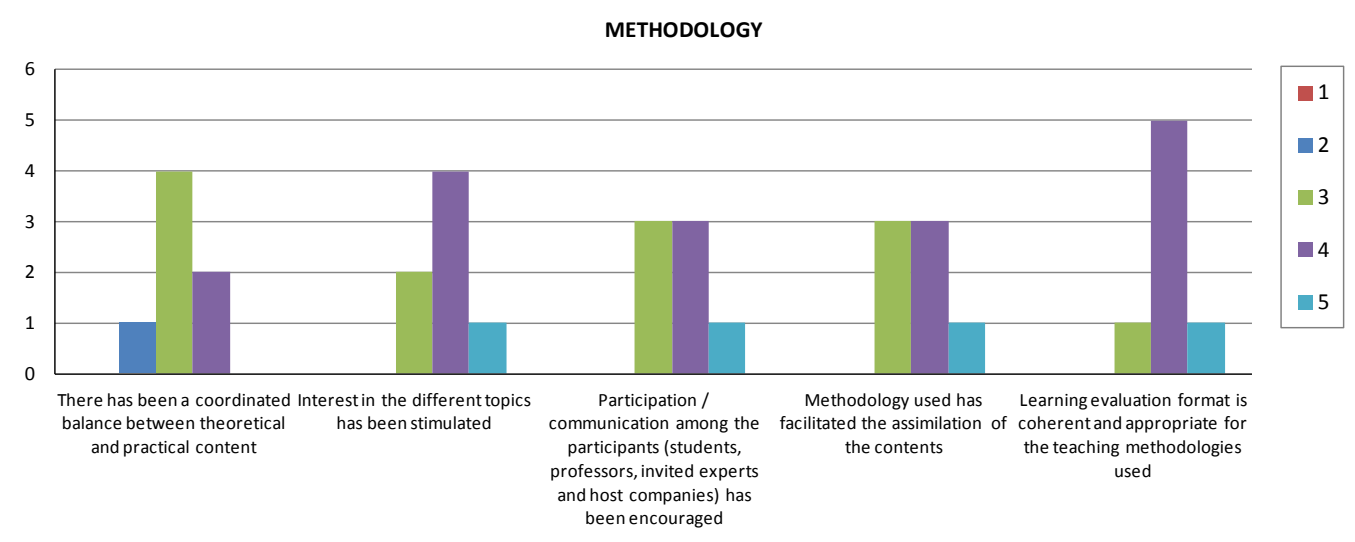

Fig. 3. Results obtained for the first sections "Methodology"

The results associated with the Teaching staff and academic coordination sections were very good, with an average of 3.9, where the most of the answers for the students were with a mark of 4 points, that is, strongly satisfied with the teaching staff and the coordination. This result corresponds to the teacher's effort to give support to the student to help them to get the maximum rendering.

TEACHING STAFF \& ACADEMIC COORDINATION

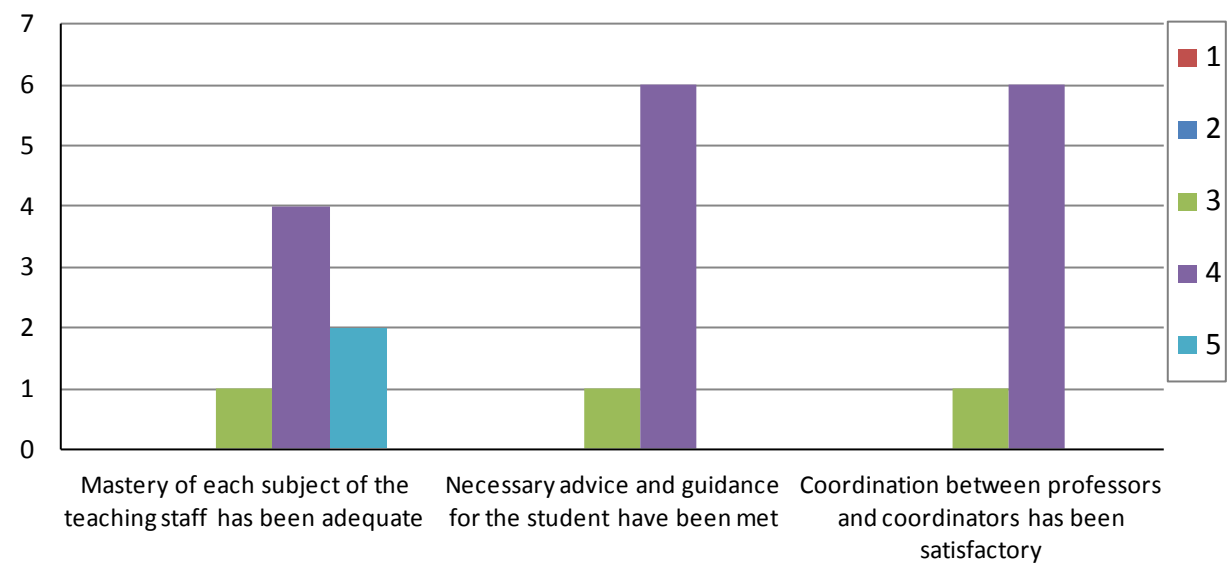

Fig. 4. Results obtained for the first sections "Teaching staff and academic coordination"

Finally, the last section focused on "Study, Dedication and Motivation", and then focused directly with the student, was the section with the lowest mark (3.7/5), although the results are also satisfactory. It is important to remark the students' satisfaction with use of ICT 
Strategies for continuous improvement in the master's degree in "Colour Technology for the automotive sector" based on feedback from graduates

resourcesto follow the course, a very important issue in this b-learning methodology. In addition, the general degree of satisfaction was very high since their degree of involvement was more than expected which is a proof of their motivation and their right attitude to learn and to get abilities for their future work.

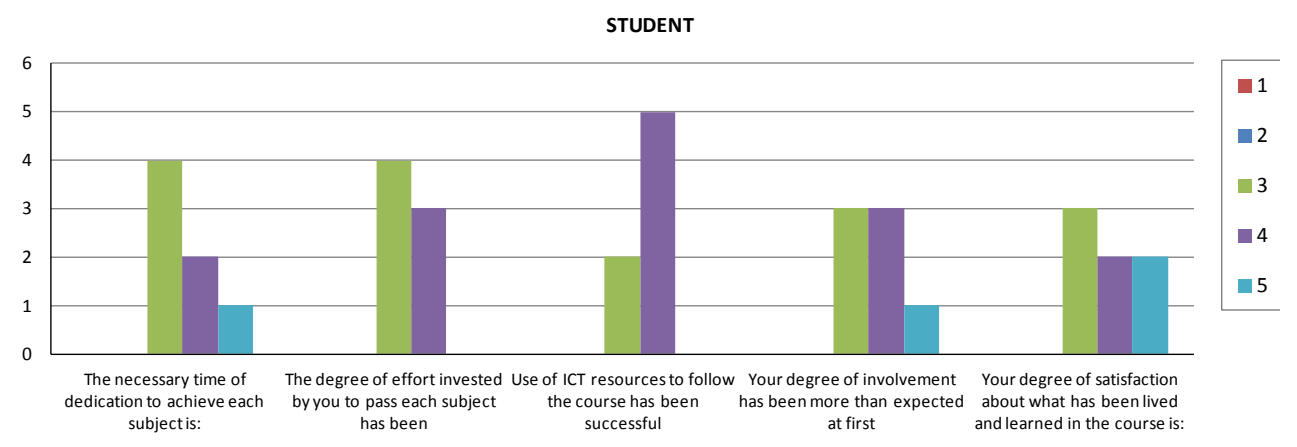

Fig. 5. Results obtained for the first sections "Student, Dedication and Motivation"

A final question was asked for students: Would you recommend this course to others? All the students would recommend the course, since the $86 \%$ of them answered this questions with a 5 (strongly agree) and the $14 \%$ of students with a 4 (agree). It is another sign of the degree of satisfaction of students.

If a deep analysis is done of this survey and each question is considered, there are some aspects to be improved in spite of these good results. In general, to have much more contact between students and tutors is a demand from students. In this way, the main channel of comunication was the Moodle platform by means of forums and messages but different virtual meeting by Adobe Connect were proposed during the course. However, the participation of this virtual meeting was low, maybe due to time difference between the participants. A possible solution to carry out the next course can be to propose individual virtual meetings in order to perform a better monitoring of students and their needs. Other critical aspect is the duration of the course and/or the distribution of tasks. The methodology proposed was to present different lessons in each subject with tasks associated with each lesson. A recommended deadline was proposed for each task although the tasks could be provided at the end of the semester. Therefore, it is a very demanding course that implies a continuous work which can be a handicap for students that combine work and studies. In order to avoid this handicap, but bearing in mind that this is a university postgraduate course, two methods of evaluation are being considered for the following course: evaluation with activities during the course (continuous evaluation) or evaluation only by means of a final exam, where the final decision is for the students according their availability. Other issue to be improved is to provide more practical sessions because this 
can increase the bridge gap between industry needs and academics. Although the teaching staff agree with this problem, it is difficult to find a proper solution. The profile of the student involved makes it difficult to further increase the number of face-to-face classes. However, teachers are considering to prepare video lectures based on practical session to show more technical topics.

\section{Conclusions}

The objective of this work was to adapt the teaching methodology to facilitate a more reflexive, participative and autonomous learning with a high degree of involvement and motivation of the students of this master course. Thus, a survey was developed with questions relating to the usefulness of the master's degree, methodology, organisation and planning of teaching, as well as a final question relating to the overall satisfaction of the course. The survey was composed by 10 questions divided into 4 sections that the student rated from 1 to 5 on a scale from "strongly disagree" to "strongly agree". The four sections analyzed obtained scores between 3.5 and 3.9 out of 5.The individual valuations were allgreater than 3 . The lowest scores were for aspects of dedication and study $(3,3)$, and to the ratio between theory and practice. However, an excellent rating (4.8/5) was obtained in the recommendation of this course to others. In addition, from the analysis of the responses, some important weaknesses were detected, such as the lack of content developed in video format, and the slowness of feedback on the results obtained in the proposed tasks. Based on these results, for next editions, it will be proposed an improvement plan that included the incorporation of videos to teaching materials, flexibility in the deadlines for activities, and the periodic monitoring of student learning and concerns through "Adobe Connect".

\section{References}

Dwi-Surjono H. (2014): The Evaluation of a Moodle Based Adaptive e-Learning System, InternationalJournal of Information and Education Technology, 4, 1, 89-92.

Fidalgo, A., Sein-Echaluce, M.L. Lerís, D., Castañeda, O. (2013): Teaching Innova Project: theIncorporation of Adaptable Outcomes in Order to Grade Training Adaptability, Journal ofUniversal Computer Science, 19, 1, 1500-1521.

García-Peñalvo, F.J., Conde, M.A., Alier, M., Casany, M.J. (2011): Opening Learning ManagementSystems to Personal Learning Environments, Journal of Universal Computer Science, 17,9, 1222-1240.

Graf, S., Kinshuk, T-C, Liu (2008): Identifying Learning Styles in Learning Management Systems byUsing Indications from Students'sBehaviour, Eighth IEEE International Conference onAdvanced Learning Technologies, 482-486. 
Strategies for continuous improvement in the master's degree in "Colour Technology for the automotive sector" based on feedback from graduates

Llorens-Largo, F., Villagrá-Arnedo, C.J., Gallego-Durán, F.J., Satorre-Cuerda, R., Compañ-Rosique, P., Molina-Carmona, R. (2016): LudifyMe: AnAdaptativeLearningModelBasedonGamification. EnCaballé, S., Clarisó, R. (eds.) Formative Assessment, Learning Data Analytics and Gamification in ICT Education. New York: Elsevier - Academic Press, cap. 12.

Martínez-Verdú, F.M. (2010). El impacto de "Bolonia": balance cuatrimestre 1, curso 1. Es hora de hacer balance, marcar prioridades para ser eficientes y aplicar gestión de conocimiento. Blog Xarxes/RedesVrPEQ-ICE. Recovered on 5 May 2012, from: http://blogs.ua.es/redesice/2010/12/28/el-impacto-de-bolonia-balance-cuatrimestre-1-curso-1/ .

OpenCourseWare UA (2009) Ciencia del color. [online] Available from http://ocw.ua.es/es/cienciasde-la-salud/ciencia-del-color-2009.html [10 May 2014].

Şimşek, O., Atman, N., İnceoğlu, M.M., Arikan, D. (2010): Diagnosis of Learning Styles Based onActive/Reflective Dimension of Felder and Silverman's Learning Style Model in a LearningManagement System, Lecture Notes in Electrical Engineering, 6017, 544-555.

Xiaoqiong, Y., Guoqing, Y., Zeng, Z. (2013): Personalized Teaching Model Based on Moodle Platform,Lecture Notes in Electrical Engineering, 216. 27-35. 